\title{
Efficacy of recombinant human soluble thrombomodulin in patients with sepsis and disseminated intravascular coagulation in the gastroenterology field
}

\author{
TOMOYASU ITO $^{1}$, AKIHITO NAGAHARA ${ }^{2}$, TARO OSADA ${ }^{1}$, JUNKO KATO ${ }^{1}$, HIROYA UEYAMA ${ }^{1}$, \\ HIROAKI SAITO $^{1}$, NOBUHITO TANIKI ${ }^{1}$, RYO KANAZAWA ${ }^{1}$, RYO SHIMIZU ${ }^{1}$, \\ JINKAN SAI $^{1}$, SHUICHIRO SHIINA ${ }^{1}$ and SUMIO WATANABE ${ }^{1}$ \\ ${ }^{1}$ Department of Gastroenterology, School of Medicine, Juntendo University, Tokyo 113-8421; \\ ${ }^{2}$ Department of Gastroenterology, Juntendo University Shizuoka Hospital, Shizuoka 410-2295, Japan
}

Received March 24, 2015; Accepted May 5, 2015

DOI: 10.3892/br.2015.464

\begin{abstract}
Recombinant human soluble thrombomodulin (rTM) was approved recently and has been used for treatment of disseminated intravascular coagulation (DIC). The aim of the present study was to evaluate the efficacy of rTM for DIC. The data of 53 inpatients with sepsis-induced DIC were retrospectively analyzed. Patients were classified into the rTM treatment group $(n=25)$ and conventional treatment group (rTM not used) was the control group ( $n=28)$. Diagnosis of DIC was made according to the criteria for acute DIC of the Japan Association of Acute Medicine. Platelet count, prothrombin time-international normalized ratio, levels of fibrin/fibrinogen degradation products (FDP), C-reactive protein and DIC scores were measured on days 0,3 and 7. Furthermore, the DIC resolution rate was assessed on days 3 and 7. Prior to treatment,

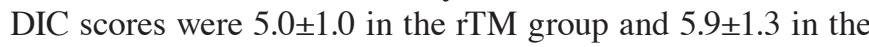
control group $(\mathrm{P}<0.05)$. Significant intra-group improvements were observed in all the parameters, except for FDP in the two groups. Significant improvements were observed in the DIC scores in the rTM group $(\Delta 2.0 \pm 1.9$ vs. $\Delta 1.5 \pm 1.9, \mathrm{P}=0.001)$. Therefore, the results suggest that rTM would be a useful medicine for treatment of DIC in the gastroenterology field.
\end{abstract}

\section{Introduction}

Disseminated intravascular coagulation (DIC) is frequently associated with a variety of conditions, such as severe infection, hematological malignancies and advanced tumors (1). In

Correspondence to: Dr Tomoyasu Ito, Department of Gastroenterology, School of Medicine, Juntendo University, 2-1-1 Hongo, Tokyo 113-8421, Japan

E-mail: tmitou@juntendo.ac.jp

Key words: recombinant human soluble thrombomodulin, sepsis, disseminated intravascular coagulation, cholangitis, gabexate mesilate addition to these diseases, numerous pathological conditions provoke DIC. Sepsis-induced DIC is life-threatening and is characterized by the systemic activation of blood coagulation that generates intravascular fibrin leading to multiple organ dysfunction syndrome and even fatality $(2,3)$.

The mortality rate in patients exhibiting DIC was higher than in those without DIC, and DIC treatment was shown to reduce mortality among patients with DIC (4-6). Thus, treatment of DIC together with therapy for the underlying diseases may be important to increase survival rates and improve the prognosis of patients with DIC.

Anticoagulant therapy to address systemic pathological thrombus formation is the principle of DIC treatment. In addition to unfractionated heparin (the mainstay of DIC treatment), low molecular weight heparin, heparinoid, synthetic protease inhibitors and antithrombin concentrates have been developed and used for the treatment of DIC.

Recombinant human soluble thrombomodulin (rTM) is a new anticoagulant agent that exerts anticoagulant and anti-inflammatory effects through the activated protein $\mathrm{C}$ (APC) pathway. Several animal studies demonstrated a reduction in mortality with the administration of rTM in a severe sepsis model $(7,8)$; however, clinical studies have been limited. rTM was approved and is being used clinically for treatment of DIC in Japan, whereas this agent is currently being evaluated in other countries.

In a phase III randomized controlled trial in Japan, significant improvement in the rate of DIC resolution in the rTM group was shown in comparison with the heparin group (9). Numerous gastrointestinal diseases cause DIC. However, the efficacy of rTM in sepsis-induced DIC remains a matter of dispute as there is limited evidence that it improves clinical outcomes.

The aim of the present study was to reveal the efficacy of rTM in patients with DIC in the gastroenterology field.

\section{Materials and methods}

Patients. Among all the patients admitted to Juntendo University Hospital between January 2009 and February 2014, 
consecutive patients who developed sepsis-induced DIC were analyzed. All the patients were treated for DIC. Protease inhibitors, low molecular heparin, antithrombin III, $\gamma$ globulin, danaparoid sodium, albumin, fresh frozen plasma and rTM were administered. The patients were divided into two groups: Those receiving rTM in addition to one or more of the other agents (rTM group) and those not receiving rTM (control group).

According to the Japanese Association for Acute Medicine (JAAM) criteria (shown in Table I), DIC was defined by a score of $\geq 4$ and DIC was considered resolved if the score reached $\leq 3$. All the patients with severe sepsis met the criteria for DIC. rTM was used at the discretion of the attending physician. In the rTM group, rTM was principally administered intravenously at a dose of $0.06 \mathrm{mg} / \mathrm{kg} /$ day and the infusion was continued until the DIC state was resolved.

Comparisons between the two groups. The variables used for comparisons of the two groups were age, gender, site of infection and DIC scores. Platelet counts, prothrombin time-international normalized ratio (PT-INR), fibrin/fibrinogen degradation products (FDP) and C-reactive protein (CRP) were measured before drug infusion and on days 3 and 7 after treatment. The JAAM DIC scores were recorded on the day the patient met the inclusion criteria for baseline values and on days 3 and 7 after study entry.

Statistical analysis. Continuous variables are expressed as group mean with standard deviation and were compared between groups with the Mann-Whitney U test. Categorical variables were analyzed by the $\chi^{2}$ test or Fisher's exact test, as appropriate. Changes in laboratory data and DIC scores of the two groups were analyzed by repeated measures analysis of variance adjusted for the baseline values as a covariate and by the post hoc Bonferroni test. $\mathrm{P}<0.05$ was considered to indicate a statistically significant difference. Statistical analyses were performed with SPSS version 17.0 for Windows (SPSS, Inc., Chicago, IL, USA).

\section{Results}

Baseline characteristics. During the study period, 53 consecutive patients were analyzed. The rTM group comprised 25 patients and the control group comprised 28 patients. Baseline characteristics of the study population and therapeutic interventions are shown in Table II. DIC scores based on JAAM criteria were significantly higher in the control compared to the rTM group. However, there were no significant differences in gender, age and site of infection between the two groups. For the rTM group, the mean duration of rTM administration was 3.6 days (range, 1.0-7.0 days).

Effect of treatment on inflammation and coagulation data. Serial changes in platelet counts, FDP, PT-INR and CRP in the two groups are shown in Table III. Significant intra-group improvement was observed for all parameters except for FDP in the two groups. However, there were no significant inter-group differences in any of the parameters examined.

Effect of treatment on DIC parameters. Serial changes in the DIC scores are shown in Fig. 1. The DIC scores improved
Table I. Japanese Association of Acute Medicine criteria for acute disseminated intravascular coagulation (DIC).

Characteristics Score

Systemic inflammatory response syndrome criteria

$\geq 3$

$0-2$

Platelet count, $\times 10^{9} / 1$

$<80$ or $>50 \%$ decrease within $24 \mathrm{~h}$ 3

$\geq 80$ and $<120$, or $>30 \%$ decrease within $24 \mathrm{~h}$

$\geq 120$

Prothrombin time (value of patient/normal value)

$\geq 1.2$

$<1.2$

Fibrin/fibrinogen degradation products, mg/l $\geq 25$ 3

$\geq 10$ and $<25$

$<10$

Diagnosis

$\geq 4$ points

DIC

Table II. Baseline characteristics of the study patients and therapeutic interventions.

\begin{tabular}{|c|c|c|c|}
\hline Characteristics & $\begin{array}{l}\text { rTM group } \\
\quad(n=25)\end{array}$ & $\begin{array}{l}\text { Control group } \\
\qquad(\mathrm{n}=28)\end{array}$ & P-value \\
\hline Gender & & & 0.71 \\
\hline Male & 13 & 16 & \\
\hline Female & 12 & 12 & 0.71 \\
\hline \multicolumn{4}{|l|}{ Age, years } \\
\hline Mean $\pm \mathrm{SD}$ & $71.6 \pm 14.7$ & $75.6 \pm 8.7$ & 0.22 \\
\hline Range & $21-85$ & $56-93$ & \\
\hline \multicolumn{4}{|l|}{ Infection site } \\
\hline Biliary tract & 15 & 20 & 0.38 \\
\hline Intestinal tract & 7 & 2 & 0.06 \\
\hline Pneumonia & 1 & 4 & 0.26 \\
\hline Others & 2 & 2 & 0.90 \\
\hline DIC scores & $5.0 \pm 1.0$ & $5.9 \pm 1.3$ & 0.005 \\
\hline \multicolumn{4}{|l|}{ Combination therapy } \\
\hline Gabexate mesilate & 15 & 26 & 0.005 \\
\hline Unfractionated heparin & 8 & 6 & 0.38 \\
\hline $\begin{array}{l}\text { Antithrombin } \\
\text { concentrates }\end{array}$ & 13 & 14 & 0.88 \\
\hline$\gamma$-globulin agent & 15 & 18 & 0.49 \\
\hline Albumin preparation & 16 & 15 & 0.44 \\
\hline Fresh frozen plasma & 1 & 4 & 0.21 \\
\hline $\begin{array}{l}\text { Duration of rTM } \\
\text { administration }\end{array}$ & $3.6 \pm 1.4$ & & \\
\hline
\end{tabular}

Data are shown as mean $\pm \mathrm{SD}$; rTM, recombinant human soluble thrombomodulin; DIC, disseminated intravascular coagulation; SD, standard deviation. 
Table III. Serial changes in the blood examination results.

\begin{tabular}{lrrr}
\hline Characteristics & Day 0 & Day 3 & Day 7 \\
\hline Platelet count, $10^{4} / \mu 1$ & & & \\
rTM & $11.1 \pm 6.5$ & $10.5 \pm 4.7$ & $17.9 \pm 9.0^{\mathrm{a}}$ \\
Control & $10.6 \pm 6.9$ & $8.4 \pm 5.7$ & $14.9 \pm 8.7^{\mathrm{b}}$ \\
PT-INR & & & \\
rTM & $1.39 \pm 0.32$ & $1.18 \pm 0.16^{\mathrm{b}}$ & $1.21 \pm 0.22^{\mathrm{b}}$ \\
Control & $1.43 \pm 0.32$ & $1.22 \pm 0.30^{\mathrm{b}}$ & $1.20 \pm 0.19^{\mathrm{b}}$ \\
FDP, $\mu \mathrm{g} / \mathrm{ml}$ & & & \\
rTM & $32.3 \pm 19.4$ & $19.8 \pm 24.5$ & $17.6 \pm 13.7$ \\
Control & $37.4 \pm 34.1$ & $24.9 \pm 14.5$ & $22.2 \pm 13.0$ \\
CRP, mg/dl & & & \\
rTM & $14.1 \pm 8.8$ & $9.7 \pm 5.4^{\mathrm{a}}$ & $6.6 \pm 5.6^{\mathrm{b}}$ \\
Control & $14.5 \pm 7.6$ & $12.2 \pm 6.1$ & $7.5 \pm 5.2^{\mathrm{b}}$ \\
\hline
\end{tabular}

Data are shown with mean \pm standard deviation. ${ }^{\mathrm{a}} \mathrm{P}<0.05$; ${ }^{\mathrm{b}} \mathrm{P}<0.01$ vs. day 0. rTM, recombinant human soluble thrombomodulin; PT-INR, prothrombin time-international normalized ratio; FDP, fibrin/fibrinogen degradation products; CRP, C-reactive protein.

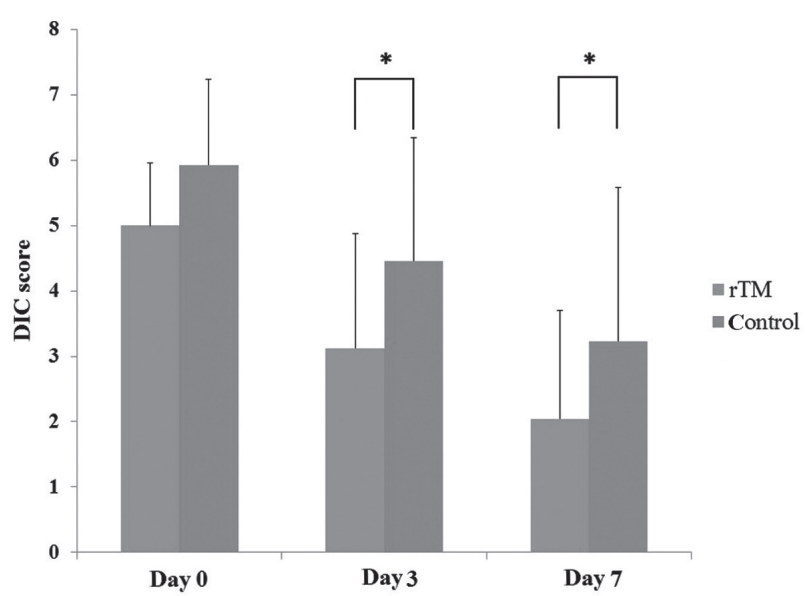

Figure 1. Changes in the disseminated intravascular coagulation (DIC) score. Significant improvements were observed in the DIC scores in the recombinant human soluble thrombomodulin (rTM) treatment group ( $\mathrm{P}=0.001)$.

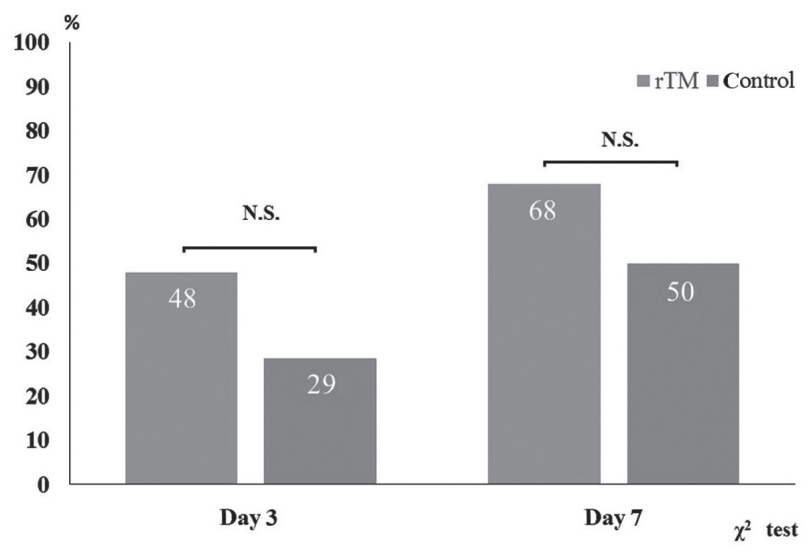

Figure 2. Disseminated intravascular coagulation (DIC) resolution rate on days 3 and 7. DIC resolution was defined by a score $\leq 3$ points. rTM, recombinant human soluble thrombomodulin; N.S. not significant. significantly in the rTM treatment group $(\mathrm{P}=0.001)$. The DIC resolution rate was assessed using JAAM criteria (Fig. 2). DIC resolution rates in the rTM group and the control group were 48 and $29 \%$ on days 3 and 68 , and $50 \%$ on day 7 , respectively. However, between group differences were not significant.

Adverse events. One adverse event associated with bleeding occurred in the rTM group but no adverse event occurred in any control group patient. The bleeding event in the rTM group was melena and did not require endoscopic hemostatic treatment. However, there was no significant difference in the incidence of this adverse event between groups.

\section{Discussion}

As DIC is a fatal disease, and immediate resolution of the DIC state should be critical. However, thus far no study has evaluated the therapeutic efficacy of rTM in the early phase. To the best of our knowledge, this is the first study to show that rTM induced early phase improvement in DIC compared to conventional therapy.

Gabexate mesilate (GM) was prescribed empirically to treat DIC and it had a positive effect. GM is a serine proteinase inhibitor that exerts an inhibitory effect on the clotting activity of thrombin and inhibits the hydrolytic reactions of thrombin and factor Xa with synthetic substrates; this agent was initially approved to treat pancreatitis and was later approved to treat DIC by the Japanese Ministry of Health, Labour and Welfare (JMHW). GM was evaluated by several studies. Umeki et al (10) reported that GM was as effective as heparin for the treatment of DIC and that it may be more successful than heparin in the treatment of DIC accompanied by bleeding diathesis. Conversely, Nishiyama et al (11) reported that GM did not inhibit coagulation or fibrinolysis and did not improve the DIC score or mortality rate in pre- or mild DIC in a limited number of patients. The administration of GM is controversial; however, it is frequently used in DIC patients even now as it does not induce bleeding.

TM is a transmembrane glycoprotein predominately expressed on the luminal surface of endothelial cells that line normal blood vessels, which are in constant contact with blood under physiological conditions. TM can bind to activated thrombin, disabling its ability to activate platelets and cleave fibrinogen. The TM-thrombin complex also cleaves protein C to APC, which in turn degrades factor Va and factor VIIIa, thus preventing further thrombin generation. Exposure of endothelial cells to inflammatory cytokines results in downregulation of TM and increased thrombogenicity, which could also contribute to the development of DIC in the setting of infection.

However, only 1 study has compared the efficacy of GM with that of rTM. Takazono et al (12) evaluated and compared the clinical efficacies of rTM and GM for the treatment of sepsis-induced DIC. In that study, the platelet counts of the rTM group significantly improved compared to the GM group. The present results are similar.

In a phase III randomized controlled trial in Japan, the JMHW diagnostic criteria for DIC were used to diagnose and assess DIC. DIC has been diagnosed using JMHW criteria for $>20$ years. However, the JAAM criteria were recently 
proposed for a simple and early diagnosis and were validated in a prospective study. Furthermore, JAAM criteria are used more frequently than JMHW criteria in clinical settings. To the best of our knowledge, this is the first study to evaluate the efficacy of rTM using JAAM criteria.

Regarding causative disease, biliary tract infection commanded a majority of the infection sites. Shimada et al $(13,14)$ reported that sepsis induced biliary tract infection in highly complicated DIC and/or multiple organ dysfunction. Therefore, therapeutic management of DIC in these patients should be a critical issue in the clinical setting.

In the two groups of the present study, GM was used in a number of cases, although a larger number of patients used GM in the control group. However, there were no significant differences between the two groups with regard to the other agents used.

In the study, DIC scores were significantly improved on day 3 and this improvement was sustained on day 7 in the rTM group compared to the control group. Regardless of the small number of cases treated with GM in the rTM group, a good treatment outcome was confirmed. This is the first study of an immediate improvement in the DIC state due to administration of rTM, as confirmed by an objective indicator, the JAAM criteria. These results indicated that rTM would be a useful medicine for treatment of sepsis-induced DIC.

Increased risk of bleeding is the greatest concern with rTM administration as well as with rAPC. However, rTM is thought to be associated with a reduction in bleeding complications in comparison with rAPC. As rTM exerts its anticoagulant effect in a thrombin-dependent manner, rTM does not activate protein $\mathrm{C}$ following inhibition of thrombin generation. In the present study, PT-INR and platelet counts improved significantly in the two groups. Furthermore, there was no significant difference in bleeding complications between the two groups. This suggested that rTM was as safe as the other drugs for DIC treatment.

The present study has certain limitations. First, this was a retrospective study and not a randomized controlled study. Second, the number of patients in the study was small compared with another larger trial, which was a randomized controlled trial.

In conclusion, rTM may significantly benefit patients with sepsis-induced DIC by achieving an early improvement in DIC.

\section{References}

1. Levi M and Ten Cate H: Disseminated intravascular coagulation. N Engl J Med 341: 586-592, 1999.

2. Levi M and van der Poll T: Inflammation and coagulation. Crit Care Med 38 (Suppl 2): S26-S34, 2010.

3. Esmon CT: The interactions between inflammation and coagulation. Br J Haematol 131: 417-430, 2005.

4. Kienast J, Juers M, Wiedermann CJ, Hoffmann JN, Ostermann H, Strauss R, Keinecke HO, Warren BL and Opal SM; KyberSept investigators: Treatment effects of high-dose antithrombin without concomitant heparin in patients with severe sepsis with or without disseminated intravascular coagulation. J Thromb Haemost 4: 90-97, 2006.

5. Wada H, Asakura H, Okamoto K, Iba T, Uchiyama T, Kawasugi K, Koga S, Mayumi T, Koike K, Gando S, et al; Japanese Society of Thrombosis Hemostasis/DIC subcommittee: Expert consensus for the treatment of disseminated intravascular coagulation in Japan. Thromb Res 125: 6-11, 2010.

6. Dhainaut JF, Yan SB, Joyce DE, Pettilä V, Basson B, Brandt JT, Sundin DP and Levi M: Treatment effects of drotrecogin alfa (activated) in patients with severe sepsis with or without overt disseminated intravascular coagulation. J Thromb Haemost 2: 1924-1933, 2004.

7. Nagato M, Okamoto K, Abe Y, Higure A and Yamaguchi K: Recombinant human soluble thrombomodulin decreases the plasma high-mobility group box-1 protein levels, whereas improving the acute liver injury and survival rates in experimental endotoxemia. Crit Care Med 37: 2181-2186, 2009.

8. Iba T, Nakarai E, Takayama T, Nakajima K, Sasaoka T and Ohno Y: Combination effect of antithrombin and recombinant human soluble thrombomodulin in a lipopolysaccharide induced rat sepsis model. Crit Care 13: R203, 2009.

9. Saito H, Maruyama I, Shimazaki S, Yamamoto Y, Aikawa N Ohno R, Hirayama A, Matsuda T, Asakura H, Nakashima M, et al: Efficacy and safety of recombinant human soluble thrombomodulin (ART-123) in disseminated intravascular coagulation: Results of a phase III, randomized, double-blind clinical trial. J Thromb Haemost 5: 31-41, 2007.

10. Umeki S, Adachi M, Watanabe M, Yaji S and Soejima R: Gabexate as a therapy for disseminated intravascular coagulation. Arch Intern Med 148: 1409-1412, 1988.

11. Nishiyama $T$, Matsukawa $T$ and Hanaoka $K$ : Is protease inhibitor a choice for the treatment of pre- or mild disseminated intravascular coagulation? Crit Care Med 28: 1419-1422, 2000.

12. Takazono T, Nakamura S, Imamura Y, Yoshioka S, Miyazaki T, Izumikawa K, Sawai T, Matsuo N, Yanagihara K, Suyama N, et al: A retrospective comparative study of recombinant human thrombomodulin and gabexate mesilate in sepsis-induced disseminated intravascular coagulation patients. J Infect Chemother 20: 484-488, 2014.

13. Shimada H, Nakagawara G, Kobayashi M, Tsuchiya S, Kudo T and Morita S: Pathogenesis and clinical features of acute cholangitis accompanied by shock. Jpn J Surg 14: 269-277, 1984.

14. Shimada H, Nihmoto S, Matsuba A and Nakagawara G: Acute cholangitis: A histopathologic study. J Clin Gastroenterol 10: 197-200, 1988 